\title{
Do Investors Pay Yield Premiums on Green Bonds?
}

\author{
Anna Mikhaylova \\ Junior analyst \\ $\underline{\text { ORCID }}$ \\ E-mail: a.y.mikhaylova@mail.ru
}

ACRA, Analytical Credit Rating Agency, Moscow, Russia

\section{Irina Ivashkovskaya}

Professor, Head of School of Finance

$\underline{\text { ORCID }}$

E-mail: iivashkovskaya@hse.ru

National Research University Higher School of Economics, Moscow, Russia

Journal of Corporate Finance Research, Vol. 14, No. 2, pp. 7-21 (2020)

DOI: https://doi.org/10.17323/j.jcfr.2073-0438.15.2.2020.7-21

Received 13 April 2020 | Peer-reviewed 15 May 2020 | Accepted 27 May 2020 


\section{Do Investors Pay Yield Premiums on Green Bonds?}

\section{Abstract}

Global shifts in perspectives on environmental concerns and the growing significance of large-scale sustainability programs have brought the issue of green financing to the fore of financial research. In terms of volume, this area has demonstrated high growth rates in various types of capital markets.

Unfortunately, few studies exist which explore the yields on green bonds in emerging markets in comparison to developed ones. As such, in this paper, we contribute new evidence to the field of green financing and outline several major differences between green issues in these types of capital markets.

We study yield premiums of green bonds on a sample of 2,450 green issues and comparable traditional bonds over the period from 2008 to March 2020. We contribute to the literature by new empirical evidence on green financing.

Our results provide evidence of small but statistically significant negative premiums on green bonds of $23,4 \%{ }^{1}$ compared to the expected yields for standard issues. We also show that the negative premium on green bonds is more pronounced in developed markets $\left(-27 \%^{2}\right)$ than in emerging ones $\left(18 \%^{3}\right)$. Moreover, we provide new evidence on the negative premium-liquidity relationship. Our research concludes that negative premiums are related to a higher level of liquidity: green bonds have lower bid-ask spreads and a higher level of liquidity than traditional ones.

These conclusions can assist investors, potential issuing companies, and public authorities in achieving a better understanding of the current situation of the green bond market in global terms.

Key words: green bonds, bond market, negative premium, environment

JEL classification: G32, G12, F01, F21, F64

\footnotetext{
${ }^{1}$ Interpretation of results in percent because of the logarithmic application of the dependent variable in the econometric model.

${ }^{2}$ Interpretation of results in percent because of logarithmic application of the dependent variable in the econometric model.

${ }^{3}$ Interpretation of results in percent because of logarithmic application of the dependent variable in the econometric model.
} 


\section{Introduction}

Due to the acute contemporary significance of environmental issues, investments in projects which mitigate environmental risks have grown increasingly relevant. Issues around 'green bonds' naturally complement strategy aimed at mitigating the consequences of climate change. This is especially the case in relation to the Paris Climate Agreement, which established new obligations for countries related to investments in the area of decarbonisation. Environmental issues are of special relevance for emerging countries where, according to estimates, annual investments of 3 trillion US dollars will be required for the period of 2016 to 2030 in order to migrate to low-carbon economies.

In comparison to the various types of traditional bonds, the specifics of green bonds (in terms of their profitability as well as their marketability) has become an important focus of investment evaluation. From $1^{\text {st }}$ July 2020 on, approximately 2,500 investment funds- those which have signed the UNO Principles for Responsible Investment - will have to invest about a half of the total amount of assets under their control, equaling approximately 45 trillion US dollars.

The existing academic research dedicated to the problems of green bonds yield generally focus on aspects such as the existence of the yield premium in the green bond market, the influence of the issue of these specific bonds on the issuer's shares price, and the presence of correlation of the bond market with other segments of the financial market $[1 ; 2 ; 3 ; 4]$. However, the rapid development of this market, as well as an increase in the number of issues in recent years, pose the problem of identifying the specific and consistent patterns of yield generation for these issues. The majority of research has been conducted using data from 2017-2018 and pertains to the period when the market for these specific bonds was at the stage of brisk growth. However, now the period of transition to the maturity stage is taking place. Moreover, the existing research is mainly dedicated to the green financing markets in developed countries, while emerging markets are discussed in academic papers very little. As such, there is a significant gap in the current academic literature.

The key motives of this research are related to the problems of price formation for green issues of corporate bonds. Are there yield premiums for green bonds or, on the contrary, are discounts made? Are there any differences in generating yield in the green bond markets in comparison to traditional issues? In which type of capital markets - e.g. those of developed or emerging countries - is this tendency most pronounced? Are there differences in liquidity level of green bonds in comparison to traditional bonds? The empirical evidence and results generated through our evaluation of the above problems represent a significant contribution to the academic literature in this area.
The article structure is as follows. In section 1, we consider the trends of the green bond market. Our review of existing academic research is presented in section 2. Section 3 is dedicated to the construction of our analytical model and the hypotheses of the research. In section 4 we outline our analysis of the results and present our conclusions.

\section{Trends of the Green Bond Market}

\section{Definition of Green Bonds and the Main Criteria for their Issue}

Green bonds are bonds whose proceeds are wholly or partially used to finance or refinance environmental projects and which comply with the principles stated in the ICMA 'Green Bond Principles' document ${ }^{4}$. Among other principles, apart from the designated purpose of the proceeds of green bonds, the ICMA document evaluates the procedure of analysis of permissible projects and the criteria of their sample, and describes the management of proceeds from green bond issues and public disclosure of information. The Green Bond Principles document distinguishes several extensive areas of projects which may be financed by means of green bonds issue, such as mitigation of climate change, adaptation to climate change, conservation of natural resources and biodiversity, prevention of pollution, and pollution control measures.

The stated criteria indicated in the Green Bond Principles contribute significantly to a better understanding by investors of the specific project's exposure to climatic risks and its potential impact on the environment.

However, not all financed environmental projects may be classified as green projects. There is no unanimous approach in the market to defining green bonds, the criteria of their estimate and taxonomy, and apart from the Green Bond Principles there is also the Climate Bond Initiative (CBI). The document issued by CBI Climate Bond Taxonomy $^{5}$ outlines the division of projects into areas and their classification. In accordance with these divisions, one can identify whether a project meets the purpose of reducing global warming by 2 degrees Celsius, as specified in the Paris Climate Agreement.

It is important to describe the considerable differences between the strategy of a company which is an issuer of green bonds and that of a company focused on getting high points for ESG components. When issuing green bonds, an investor who is focused on the characteristics of the issue itself (in accordance with the Green Bond Principles, the issuing company need not be entirely environmentally compliant in order to issue green bonds), while an investor who is focused on investing into companies with high ESG indicators will pay attention to the issuer's characteristics in particular.

\footnotetext{
${ }^{4}$ URL: https://www.icmagroup.org/green-social-and-sustainability-bonds/green-bond-principles-gbp/

${ }^{5}$ URL: https://www.climatebonds.net/standard/taxonomy
} 


\section{The Main Trends and Prospects of Development of the Green Bond Market}

The first green bonds were issued in 2007 by the European Investment Bank. Since that time, the green bond market has been developing rapidly, both from the point of view of the total scope of issued obligations and from the point of view of issuers' structure. For example, Poland was the first country to issue green bonds at the sovereign level in 2016. In 2017, the American mortgage association Fannie Mae made one of the largest green bond issues (worth 24.9 billion US dollars) in the form of securitization bonds. In June 2017, an issuer from Malaysia made the first issue of green Islamic bonds (known as 'green Sukuk'). Thereafter, the structure of green bond issuers expanded, including supranational authorities, corporate institutions, pension funds, commercial banks, non-financial entities, and municipal authorities.

In recent years, the green bond market has grown rapidly. In 2019, for example, the total amount of green bond issues increased by $53 \%$ in comparison to the previous year and exceeded 200 billion US dollars ${ }^{6}$.

Out of the possible reasons for the rapid development of green bonds, we can distinguish ${ }^{7}$ a better understanding of the relation between the climate change and its potential influence on the financial system. This may be seen to be characterised in terms of investor support (as well as political support) in relation to the signing of the Paris Climate Agreement by approximately 200 countries in 2015.

Corporate institutions and financial institutions accounted for a plurality of issues in 2019. Investors from several regions declared an excess of demand for green bonds issued, in particular by corporate issuers ${ }^{8}$. In terms of regions, the largest share of issues in 2019 fell to European countries (approximately 45\%), followed by the Asian-Oceanian countries, and North America. In 2019 the largest part of proceeds from green bond issues was invested in the projects related to the power industry, construction, and transport. It is most likely that for the foreseeable future the existing structure of issues by industries and regions will not undergo significant changes.

According to a forecast from Moodys ${ }^{9}$, the amount of green bond issues in 2020 may achieve 300 billion US dollars. Attaining the sustainable development goals declared by UNO requires a significant economics decarbonization, and as such the convenience potential for financing projects by means of green bonds is significant. As a result, there is a substantial potential for growth of the green bond market, due particularly to emerging-economy countries where environmental issues are still acute. Development of the green bond market in the medium term may be contingent upon the following factors: support from governments (privileges, subsidies, other easing of some requirements), reduction in the cost of environmentally-friendly technology which will make its application more economically viable, the question of price dynamics for key energy resources, and the question of prices for carbon dioxide emission quotas ${ }^{10}$. Analyzing the structure of projects according to the areas in which investments are made through green bonds, one can see that in such sectors as industrial production, an apparently inadequate level of funding is observed. In the coming years, a growth in green bond issues by financial institutions ${ }^{11}$ is possible because the amount of credits issued for the funding of projects in the area of sustainable development will grow rapidly. In the years ahead, a decrease of the rate of growth of the green bond market may be related to both a transition of the market into the maturity stage and a 'cannibalism' process, accounting for the growing segment of social bonds and bonds aimed at funding sustainable development projects - i.e. sustainability bonds (the total volume of the market of green bonds, social bonds and sustainability bonds at the end of 2019 is evaluated by CBI as 400 billion US dollars. However, against the background of the combined debt market, the share of green, social and sustainability bonds is still insignificant (approximately $5 \%)$. Other factors which may adversely affect the demand of supply for green bonds are information asymmetry, insufficient qualifications of some market players (for example, verifiers) and an excessive tightening of the regulations and procedures necessary to be implemented in order to issue bonds. Among the factors which have a detrimental effect on the market at its present stage of development are the absence of a unified regulation and unified standards of the market, greenwashing, and a low quality of furnished public information (it is necessary to provide for its disclosure on a regular basis).

Thus, in spite of certain challenges for development (from a regulatory point of view, e.g. the absence of universally-acknowledged standards, the greenwashing problem, and the problem of professional qualification of some players) the green bond market is developing rather rapidly. Green bond issuers are substantially diversified by sectors, regions of location, and types of borrowers.

\footnotetext{
${ }^{6}$ Calculations were made on the basis of the green bond database of Thomson Reuters.

${ }^{7}$ Banga J. The green bond market: a potential source of climate finance for developing countries, 2019.

${ }^{8}$ CBI (2019). Green Bond. European Investor Survey. URL: https://www.climatebonds.net/resources/reports/green-bond-european-investorsurvey-2019

${ }^{9}$ URL: https://www.moodys.com/research/Moodys-Green-social-and-sustainability-bond-issuance-to-jump-24--PBC_1212910

${ }^{10}$ In a series of regions/countries/cities various systems are in force which aim at stemming emissions of CO2 into the atmosphere (such as emissions trading system, carbon dioxide tax).

${ }^{11}$ S\&P (2019) Green Finance: Modest 2018 Growth Masks Strong Fundamentals for 2019.
} 


\section{Literature Review}

An important part of the literature review is the analysis of "fundamental" articles studying the factors which have an impact on the yield of bond issues in different countries in various years. To analyse the influence channels of green bond issues on issuers, we considered research on the response of shares price of issuing companies to information about the bond issue. In the majority of considered articles [1;3-8] discounts on green bond yields are shown. These yield discounts may be contingent upon a lower risk of such securities because investors who are oriented toward investments meeting the sustainable development criteria are the ones interested in it. Besides, such investors may be targeted by means of long-term retention of securities in the portfolio. This may reduce the trade volumes of these issues in the secondary market and, as a consequence, result in a greater price stability. However, a series of authors have investigated the comparability of yield spreads of green bonds to traditional bonds adjusted for volatility [5]. Another argument for the existence of a negative spread to green bond yield is excess of demand over supply in this market segment, caused by the intrinsic characteristics of green bonds, or their insufficiency in the market at present.

The distinctive features of green bond issuers are subject to significant analysis in the academic literature. In the article [9] factors which influence the amount of borrowing through green bonds is analysed using a sample from 2010-2017. It is shown that the amount of one-time green bond issues is largely defined by standard factors: e.g. the coupon rate, credit rating, pledged collateral, state of the industry sector where the issuer operates, and the financial status of the company itself. The biggest rate of growth of green bond issues was characteristic of markets in emerging countries', especially the issues made in national currency, for example, in yuans. The authors emphasise the heteroscedasticity of the developed and emerging market of green bonds, which is indicative of the fact that in order to regulate such markets various methodologies and policies should be applied. Another significant characteristic is the goodwill of the issuing company and the existence of verification of compliance with the principles of green financing. The analysis shows that yield discounts and a higher marketability are characteristic of green bonds from institutional issuers, in comparison to commensurable issues of traditional bonds. However, issues from private issuers show positive premiums and lower liquidity levels [10]. The authors analysed issues in greater detail from private issuers and found out that there were significant premiums in the issues which did not have an official confirmation of compliance with Green Bond Principles and other verifications.

The influence of the liquidity level is considered in many papers $[1 ; 11]$. The authors use adjustments to calculate the liquidity of the analysed issues. They indicate that an active involvement of investment funds and other institutional investors at the stage of their issue (the primary market), and possession of these assets up to the point of maturity results in a decrease of trading and, as a consequence, a decrease in liquidity [4]. It is important to take into consideration the liquidity factor, because a yield of the issues which are not actively traded in the market may differ from the market level for such securities, and this may potentially result in a distortion of the obtained results.

\section{The Fundamental Factors which influence the Yield Spread of the Issued Bonds}

In order to enhance understanding of the topic and construct a more accurate model, it is necessary to study the factors which in the majority of cases influence the rates of return of corporate bonds. On the basis of the considered articles [12-22] one can make a conclusion that macroeconomic indicators, and the individual characteristics of issues and issuing companies have a significant impact on the yield factor, while the sectoral affiliation and the location country's characteristics are not always of significance.

\section{Research Model}

\section{Hypotheses and Variable Models}

On the basis of the literature analysis, we propose the following hypotheses:

\section{H1: Investors pay premiums on green bonds.}

H2: There is no substantial difference between the liquidity of green bonds and commensurable traditional issues.

H3: Yield premiums of green bonds of issuers from developed and emerging countries differ. In the issues made by issuers from developed countries, the yield premium on green bonds is more pronounced.

In order to test these hypotheses, we made a sample comprising corresponding issues made as of March 2020 from the Thomson Reuters database. We selected the commensurable bonds for comparison by means of sorting out the issues in the Cbonds platform. This was done in order to provide for intercomparison with the green bonds sample according to the following criteria: year of issue, issuer's sectoral affiliation, country of issue, coupon rate, credit rating level, and Macaulay duration or modified duration. In total, the initial sample comprised 3,477 observations (issues) within the period of 2007 to 2020, of which green bonds account for approximately 600 of them, the rest are the commensurable "classical" issues. As long as the information on the issuer's credit rating, and the difference between the bid and ask prices was not available for all selected issues, and these regressors, according to our opinion and literature analysis, may have a significant impact on the dependent variable OAS, the initial sample was reduced to 2,450 observations for which we have all necessary data. 
For our evaluation, we used models 1 and 2 represented by the formulas below:

$$
\begin{aligned}
& \mathrm{OAS}_{\mathrm{i}}=\beta_{0}+\beta_{1} \cdot \mathrm{CPN}_{\mathrm{i}}+\beta_{2} \cdot \mathrm{ISS}_{-} \mathrm{DATE}_{\mathrm{i}}+\beta_{3} \cdot \mathrm{AMM}_{-} \mathrm{ISS}_{\mathrm{i}}+\beta_{4} \cdot \mathrm{ISS}_{-} \mathrm{PR}_{\mathrm{i}}+ \\
& +\beta_{5} \cdot \mathrm{TEN}_{\mathrm{i}}+\beta_{6} \cdot \mathrm{MIN} \_\mathrm{DEN}_{\mathrm{i}}+\beta_{7} \cdot \mathrm{MOD}_{-} \mathrm{DUR}_{\mathrm{i}}+\beta_{8} \cdot \mathrm{MAC}_{-} \mathrm{DUR}_{\mathrm{i}}+ \\
& +\beta_{9} \cdot \mathrm{AMM}_{-} \mathrm{OUT}_{\mathrm{i}}+\beta_{10} \cdot \mathrm{BID}_{-} \mathrm{ASK}_{\mathrm{i}}+\beta_{11} \cdot \mathrm{RATING}_{\mathrm{i}}+\beta_{12} \cdot \mathrm{GB}_{\mathrm{i}}+ \\
& +\beta_{13} \cdot \mathrm{MKT}_{-} \mathrm{ISS}_{\mathrm{i}}+\beta_{14} \cdot \mathrm{CPN} \_\mathrm{FR}_{\mathrm{i}}+\beta_{15} \cdot \mathrm{GDP}_{\mathrm{i}}+\beta_{16} \cdot \mathrm{CPI}_{\mathrm{i}}+ \\
& +\beta_{17} \cdot \mathrm{RATE}_{\mathrm{i}}+\varepsilon_{\mathrm{i}} \\
& \mathrm{BID}_{-} \mathrm{ASK}_{\mathrm{i}}=\beta_{0}+\beta_{1} \cdot \mathrm{OAS}_{\mathrm{i}}+\beta_{2} \cdot \mathrm{CPN}_{\mathrm{i}}+\beta_{3} \cdot \mathrm{ISS}_{-} \mathrm{DATE}_{\mathrm{i}}+ \\
& +\beta_{4} \cdot \mathrm{MOD}_{-} \mathrm{DUR}_{\mathrm{i}}+\beta_{5} \cdot \mathrm{MAC}_{-} \mathrm{DUR}_{\mathrm{i}}+\beta_{6} \cdot \mathrm{AMM}_{-} \mathrm{OUT}_{\mathrm{i}}+\beta_{7} \cdot \mathrm{RATING}_{\mathrm{i}}+ \\
& +\beta_{8} \cdot \mathrm{GB}_{\mathrm{i}}+\beta_{9} \cdot \mathrm{MKT}_{-} \mathrm{ISS}_{\mathrm{i}}+\beta_{10} \cdot \mathrm{CPN}_{-} \mathrm{FR}_{\mathrm{i}}+\varepsilon_{\mathrm{i}}
\end{aligned}
$$

The variables used in the econometric analysis are defined as follows.

The first dependable variable, OAS (Option - Adjusted Spread) was calculated as the spread of yield of the analysed issue, and the yield of commensurable risk-free bonds (traditionally OAS is calculated using the same values of riskless rates as are used for the calculation of Z-spread, i.e. non-coupon ones). The values of the OAS variable for the analysed issues were taken by the authors from the Thomson Reuters database.

This spread is adjusted to take into consideration the possible inherent put or call options by taking into consideration the probable expenses for these issues (OAS=Zspread-Option cost). When discounting cash flows from a bond issue for the riskless rate plus OAS, the value of the discounted cash flows from a bond is considered equivalent to its current cost. OAS is measured in percentage points. In the econometric analysis given below, in order to test the first hypothesis (regarding the existence of the negative return on green bonds in comparison with the commensurable traditional ones) OAS will serve as the dependent variable.

The second dependent variable BID_ASK (Liquidity Estimation) serves as a proxy to measure the degree of liquidity of the issue (it is calculated as a bid-ask spread (the difference between the ask and bid price) for this issue as of March 2020. The less the difference between the bid and ask price, the more active the trading for this issue is, and it is indicative of a higher liquidity. We suggest that a higher liquidity of an issue is indicative of a greater investors' demand, and hence in case of a greater demand the yield spread decreases.

CPN (Coupon) is the coupon rate of a bond issue in per year terms and is measured in percentage terms. All other things being equal, the coupon rate may have a positive impact on OAS value.

ISS_DATE (Issue Date) is the year of a bond issue. It is anticipated that the variable of the issue year has no direct impact on the issue's rate of return, but the macroeconomic situation at a certain time and dynamics of development and popularisation of the green bond trend with the passing of the years may leave their traces. Further, we can clusterise issues by years of issue for a more detailed study of inherent trends.

AMM_ISS (Amount Issued) is the issue volume within the designated issue expressed in US dollars. Usually, large companies make greater bond issues. As long as 'size' is one of the business solvency factors (as a rule, large companies are at the maturity stage of their life cycle, have a more sound market position, more steady cash flows and, in general, a more conservative financial policy) investors often perceive small companies as more risky. This is due to smaller companies' perceived greater volatility of revenue/less operating efficiency, a lower position in the market or a shorter history, and the fact that investors often require higher rates of return for the bond issues of such companies in order to offset the risk. In general, owing to their size and the opportunity to borrow larger sums in the public market, due to presence of demand those companies of a greater size which are well-established and well-known account for larger issues. So, we make an assumption that the amount of issue influences the OAS size negatively.

MKT_ISS (Market of Issue) is a binary variable which designates the market at which the bonds have been issued (1 - the bonds have been issued in the international market, 0 - the bonds have been issued in the internal "domestic" market). In view of the different degrees of development of financial markets of various countries, different markets endowments, different levels of financing education on green topics, and the fact that demand for bond issues and their liquidity may vary greatly among countries. As a general matter, the international bond market, e.g. the eurobond market, is better developed, characterised by greater investors' demand, greater marketability, and often, low rates. We presume that for the bonds issued in the international market, the required yield is lower.

CPN_CLASS (Coupon Class) is a binary variable which designates the coupon type ( 1 - a fixed rate, 0 - a floating rate). Influence of this variable on OAS will to a great extent depend on the current macroeconomic environment at the date of issue, investors' expectations, and time interest rate structure in the economics at the date of issue. However, in the general case, we make the assumption 
that with the floating rate of the coupon the investor faces a greater uncertainty, and as a consequence, a greater risk, and against this background the rate of return required by the market will be greater.

CPN_FR (Coupon Frequency) is a binary variable which designates the coupon payment frequency ( 1 - annually, 0 - otherwise) (mainly by half years). In our opinion, there is no question of a straightforward influence of this regressor on OAS, however, in order to exclude the possibility of its significant influence, we think it expedient to add this variable in the initial model specification.

ISS_PRICE (Issue Price) is the nominal price when bonds are issued, and it is measured in percent. All other things being equal, a lower price than the nominal one for an issue means a higher revenue from investors, consequently, we anticipate an adverse influence of this variable on OAS.

TEN (Tenor) is the number of years till the issue maturity and is measured in years. The direction of influence of this variable on the rate of return required by the investors depends on the prevailing interest rate structure at the date of issue. However, in general, we assume a positive dependence of percentage rates on the investment horizon. Considering the problem from this point of view, we presume that the longer the maturity period, the greater the real effective yield of the issue is.

MIN_DEN (Minimum Denomination) is the minimal sum for which trading is accepted as regards a certain issue per one person or legal entity and is measured in US dollars. By analogy to the variable designating the issue volume, we anticipate that large companies make greater issues and account for a larger segment of the minimal trading amount. The negative dependence between the mentioned factor and OAS follows from the logic stated above.

MAC_DUR (Mac. Duration)- Macaulay duration, a predicted value. Basically, we presume that the higher the duration, the bigger the interest risk and greater OAS spread.

AMM_OUT (Amount Outstanding) - the volume of a certain issue in circulation at present, in US dollars.

GB (Green_Bond) is a binary variable (1 - in case of green bonds and 0 - otherwise).

RATING (Credit rating) is the numerical value of ratings of the top three of rating agencies for a certain issue. In order to calculate this indicator, the ratings were transferred from the literal expression into the integral equivalent (see appendix 1) and for each issue a mean value was taken between the Moody`s, S\&P, and Fitch ratings. We assume that the higher the rating, the greater the company credit quality, and therefore the lower the rate of return required by the market for this issue. A transformation of the literal rating scales into integral ones is also taken into account. GDP (Gross Domestic Product Growth Rate) is the USA gross domestic product growth rate which corresponds to the year of issue and is measured in terms of percent.

CPI (Consumer Price Index) is the USA consumer price index for the corresponding year and is also measured in percent.

RATE (Interest Rate) it is a proxy variable for the rate of borrowing of the USA banks.

\section{Analysis of the Sample and Descriptive Statistics}

In order to obtain a more accurate model, the data was purged of outlying data. The descriptive statistics after data preprocessing is represented in Table 1.

In order to obtain a more accurate model, the data sample was purged out outlying data. So, the values of the OAS variable less than zero and exceeding 1,000 were eliminated, the values of the coupon variable exceeding $11.71 \%$ were eliminated. The iss_pr variable was cleared from outlying data less than 95 and exceeding 103, the min_den variable values exceeding 1,000,000 as well as the values of observations with the modified duration exceeding 20, and the Macaulay duration values exceeding 19.8 and bid_ask values exceeding 2.5 were eliminated. All the above transformations did not go beyond the $80^{\text {th }}$ percentile if outlying data was eliminated from above or $10^{\text {th }}$ percentile when the outlying data was eliminated from below.

The first research hypothesis, as to green bonds having yield premiums, was tested using the logarithmic form of the dependent variable. Based on the findings of the multicollinearity verification using the Variance Inflation Factor (VIF), and constructing the pair correlation matrix for the analysed parameters, we eliminated from the model the regressors amm_iss and mod_dur which have a very high correlation with amm_out and mac_dur, respectively, but do not influence or have a little influence upon the dependent variable. The regression analysis established that at a 5\% level the regressors iss_pr,ten, mkt_iss, gdp were insignificant, and so they were eliminated from the model. Thus, in the specified model all regressors are of significance at a $5 \%$ level. The Breusch-Pagan and White tests reject the hypothesis of homoscedasticity and are indicative of the presence of heteroscedastic errors in the model. In order to eliminate such errors from the model we used the standard error correction according to the White method in order to obtain robust standard errors.

As we can see from the obtained results in Table 2, the variable responsible for the bond being green or not is significant at a $1 \%$ level. Therefore, the suggested hypothesis of the presence of a negative yield premium on green bonds is not rejected. Based on the results of the obtained model we conclude that with green bonds, the spread reduces by $23.4 \%{ }^{12}$. 
Table 1. Descriptive Statistics of the Sample

\begin{tabular}{|c|c|c|c|c|c|c|c|c|c|c|}
\hline & $\mathbf{N}$ & $\min$ & p25 & Mean & St.Dev & variance & $\mathrm{cv}$ & Median & p75 & $\max$ \\
\hline Oas & 2,293 & 5.233 & 77.474 & 148.13 & 111.717 & $12,480.58$ & .754 & 126.506 & 185.559 & 927.023 \\
\hline bid ask & 2,293 & 0 & .129 & .381 & .37 & .137 & .972 & .267 & .5 & 2.5 \\
\hline Cpn & 2,293 & 0 & .875 & 2.294 & 1.612 & 2.599 & .703 & 2.15 & 3.4 & 9.5 \\
\hline iss date & 2,293 & 2008 & 2015 & 2016.162 & 1.886 & 3.556 & .001 & 2016 & 2017 & 2020 \\
\hline amm iss & 2,293 & 141,000 & $2.82 \mathrm{e}+08$ & $7.25 e+08$ & $6.18 \mathrm{e}+08$ & $3.82 \mathrm{e}+17$ & .853 & $5.72 e+08$ & $1.00 \mathrm{e}+09$ & $3.00 \mathrm{e}+09$ \\
\hline iss $\mathrm{pr}$ & 2,293 & 96.05 & 99.589 & 99.752 & .419 & .176 & .004 & 99.853 & 100 & 103 \\
\hline Ten & 2,293 & 1 & 1 & 3.878 & 2.614 & 6.832 & .674 & 5 & 6 & 9 \\
\hline min den & 2,293 & 1 & 1,000 & $88,861.89$ & 153000 & $2.33 e+10$ & 1.717 & 100,000 & 100,000 & $1,000,000$ \\
\hline mod dur & 2,293 & .008 & 1.833 & 4.295 & 3.404 & 11.586 & .793 & 3.833 & 5.864 & 19.573 \\
\hline mac dur & 2,293 & .008 & 1.882 & 4.466 & 3.56 & 12.672 & .797 & 3.931 & 6.025 & 19.786 \\
\hline amm out & 2,293 & 48,000 & $2.76 \mathrm{e}+08$ & $7.14 \mathrm{e}+08$ & $6.13 e+08$ & $3.76 \mathrm{e}+17$ & .859 & $5.63 e+08$ & $1.00 \mathrm{e}+09$ & $3.00 \mathrm{e}+09$ \\
\hline rating & 2,293 & 1 & 4.33 & 5.679 & 2.83 & 8.009 & .498 & 5.67 & 7.67 & 15.5 \\
\hline $\mathrm{Gb}$ & 2,293 & 0 & 0 & .29 & .454 & .206 & 1.563 & 0 & 1 & 1 \\
\hline mkt iss & 2,293 & 0 & 0 & .316 & .465 & .216 & 1.472 & 0 & 1 & 1 \\
\hline cpn fr & 2,293 & 0 & 0 & .514 & .5 & .25 & .972 & 1 & 1 & 1 \\
\hline gdp & 2,293 & -2.5 & 1.6 & 2.232 & .662 & .439 & .297 & 2.4 & 2.5 & 2.9 \\
\hline cpi & 2,293 & -.3 & 1.3 & 1.543 & .735 & .54 & .476 & 1.6 & 2.1 & 3.8 \\
\hline rate & 2,293 & 3.3 & 3.3 & 3.905 & .653 & .426 & .167 & 3.5 & 4.1 & 5.3 \\
\hline
\end{tabular}

Source: Author's own calculations. 
Table 2. Final Specification of Model 1

\begin{tabular}{|c|c|}
\hline Variables & $\begin{array}{l}\text { After specification and elimina- } \\
\text { tion of heteroscedastic errors }\end{array}$ \\
\hline \multirow[t]{2}{*}{ Cpn } & $0.0791 * * *$ \\
\hline & $(0.00757)$ \\
\hline \multirow[t]{2}{*}{ iss_date } & $0.0110 * *$ \\
\hline & $(0.00538)$ \\
\hline \multirow[t]{2}{*}{ min_den } & $1.02 \mathrm{e}-07 * *$ \\
\hline & $(5.10 \mathrm{e}-08)$ \\
\hline \multirow[t]{2}{*}{ mac_dur } & $0.0344 * * *$ \\
\hline & $(0.00273)$ \\
\hline \multirow[t]{2}{*}{ amm_out } & $5.04 \mathrm{e}-11 * * *$ \\
\hline & $(0)$ \\
\hline \multirow[t]{2}{*}{ bid_ask } & $0.0761 * * *$ \\
\hline & $(0.0239)$ \\
\hline \multirow[t]{2}{*}{ Rating } & $0.166 * * *$ \\
\hline & $(0.00424)$ \\
\hline \multirow[t]{2}{*}{$\mathrm{Gb}$} & $-0.234 * * *$ \\
\hline & $(0.0206)$ \\
\hline \multirow[t]{2}{*}{ Cpi } & $0.0276 * *$ \\
\hline & $(0.0130)$ \\
\hline \multirow[t]{2}{*}{ Constant } & -18.68 \\
\hline & $(11.71)$ \\
\hline Observations & 2,293 \\
\hline R square & 0.7334 \\
\hline $\begin{array}{l}\text { R square } \\
\text { norm. }\end{array}$ & 0.7323 \\
\hline F-statistics & 697.65 \\
\hline P-value & 0.0000 \\
\hline
\end{tabular}

Robust standard errors in the brackets

${ }^{* * *} \mathrm{p}<0.01,{ }^{* *} \mathrm{p}<0.05,{ }^{*} \mathrm{p}<0.1$

Source: Author's own calculations.

The second hypothesis, on the differences in marketability between green bonds and commensurable traditional issues, was tested using the same sample, and the descriptive statistics and the process of eliminating outlying data coincide with the procedures described above. Due to the fact that the logarithmic form of the dependent variable describes our data better, the decision was taken to compare the models' functional forms. In order to define the best functional form we conducted the Box-Cox test, on the basis of which we may use the logarithmic specification.
Before defining the optimal set of regressors, we conduct the multicollinearity verification by means of the Variance Inflation Factor (VIF) evaluation. The mod_dur regressor was eliminated from the model immediately because of its high relation with the regressor responsible for the Macaulay duration. In specified model 2 all regressors are significant at a 5\% level. The Breusch-Pagan and White tests reject the hypothesis of homoscedasticity and are indicative of the presence of heteroscedasticity-related errors in the model. In order to eliminate such errors from the existing model we used the standard error correction according to the White method in order to obtain robust standard errors. The results of this standard errors correction are offered in Table 3 below.

Table 3. Final Specification of Model 2

\begin{tabular}{|c|c|}
\hline Variables & $\begin{array}{l}\text { After specification and elim- } \\
\text { ination of heteroscedasticity } \\
\text { errors }\end{array}$ \\
\hline \multirow[t]{2}{*}{ Oas } & $0.00146 * * *$ \\
\hline & $(0.000291)$ \\
\hline \multirow[t]{2}{*}{ Cpn } & $0.0583 * * *$ \\
\hline & $(0.0221)$ \\
\hline \multirow[t]{2}{*}{ iss_date } & $0.0639 * * *$ \\
\hline & $(0.0136)$ \\
\hline \multirow[t]{2}{*}{ mac_dur } & $0.158 * * *$ \\
\hline & $(0.00662)$ \\
\hline \multirow[t]{2}{*}{ amm_out } & $-1.72 \mathrm{e}-10 * * *$ \\
\hline & $(0)$ \\
\hline \multirow[t]{2}{*}{ Rating } & $0.0798 * * *$ \\
\hline & $(0.0106)$ \\
\hline \multirow[t]{2}{*}{$\mathrm{Gb}$} & $-0.479 * * *$ \\
\hline & $(0.0443)$ \\
\hline \multirow[t]{2}{*}{ mkt_iss } & $0.136 * * *$ \\
\hline & $(0.0420)$ \\
\hline \multirow[t]{2}{*}{ cpn_fr } & $0.566 * * *$ \\
\hline & $(0.0713)$ \\
\hline \multirow[t]{2}{*}{ Constant } & $-131.9 * * *$ \\
\hline & $(27.41)$ \\
\hline Observations & 2,287 \\
\hline R square & 0.4720 \\
\hline R square norm. & 0.4699 \\
\hline F-statistics & 226.13 \\
\hline P-value & 0.0000 \\
\hline
\end{tabular}

Robust standard errors in the brackets

${ }^{\star * *} \mathrm{p}<0.01,{ }^{* *} \mathrm{p}<0.05,{ }^{*} \mathrm{p}<0.1$

Source: Author's own calculations. 
As we can see from the obtained results, the variable responsible for the bond being green or not is significant at a $1 \%$ level. The hypothesis of absence of differences in the degree of marketability of green and traditional bonds is rejected. On the basis of the results of the obtained model, we observe that for green bonds the bid-ask spread decrease amounts to $47.9 \%$, and this is traditionally considered to be a proof of a higher liquidity (a lesser value of difference between the bid and ask prices is usually contingent upon larger volumes of trading for these securities). A higher degree of liquidity of green bond issues may potentially be indicative of a more active trading of these issues.

Hypothesis 3 concerns the differences in the amount of the yield premium on green bond issues from developed and emerging countries. The hypothesis is based upon the assumption that for those issues which are identified by different issuers' categories from developed countries (due to the maturity of their financial markets), greater numbers of investors stand ready to invest in green bonds.
A lower country risk, operational risk, and currency risk means the negative yield premium on green bonds will be larger (higher by modulo).

In order to verify hypothesis 3, we expanded the initial sample and divided it into two sub-samples on the basis of the issuing company's geographical affiliation. These sub-samples comprise 4,444 issues from developed countries and 790 issues from emerging countries. The difference in the number of observations in the two sub-samples is mainly related to the prevailing number of green bonds made by issuers from developed countries, so as a result we included in this sample a greater number of commensurable issues. The variables used in the model align with those mentioned above, except for the bid-ask variable, and this is contingent on an insufficient amount of information in the Thomson Reuters database as regards the indicators used as a proxy for marketability of new bond issues. The descriptive statistics of the sample for developed countries is represented in Table 4, and for emerging countries - in Table 5. 
Table 4. Descriptive Statistics of the Sub-Sample of Developed Countries

\begin{tabular}{|c|c|c|c|c|c|c|c|c|}
\hline & $\mathbf{N}$ & $\min$ & p25 & Mean & St.Dev & variance & p75 & $\max$ \\
\hline oas & 4,444 & 0.584373 & 83.76882 & 177.6368 & 159.6136 & $25,476.49$ & 203.2341 & 1366.196 \\
\hline iss date & 4,444 & 2009 & 2016 & 2017.447 & 1.963576 & 3.855632 & 2019 & 2020 \\
\hline cpn & 4,444 & -0.5 & 0.655 & 2.146406 & 1.695252 & 2.873881 & 3.25 & 11.71 \\
\hline amm iss & 4,444 & 61,466 & $2.17 \mathrm{E}+08$ & $6.79 \mathrm{E}+08$ & $6.28 \mathrm{E}+08$ & $3.95 \mathrm{E}+17$ & $1.00 \mathrm{E}+09$ & $5.40 \mathrm{E}+09$ \\
\hline iss pr & 4,444 & 81.07 & 99.61 & 99.80585 & 0.8785466 & 0.7718441 & 100 & 111.5 \\
\hline ten & 4,444 & 1 & 3 & 6.84766 & 6.364604 & 40.50818 & 8 & 50 \\
\hline min den & 4,444 & 0.01 & 2,000 & $105,740.7$ & $245,463.5$ & $6.03 \mathrm{E}+10$ & 100,000 & $2,000,000$ \\
\hline mod dur & 4,444 & 0.002777 & 2.563743 & 5.729794 & 4.492593 & 20.18339 & 7.313456 & 24.8344 \\
\hline mac dur & 4,444 & 0.002778 & 2.662372 & 5.907454 & 4.57491 & 20.92981 & 7.532564 & 24.97629 \\
\hline amm out & 4,444 & 0 & $2.13 \mathrm{E}+08$ & $6.68 \mathrm{E}+08$ & $6.14 \mathrm{E}+08$ & $3.78 \mathrm{E}+17$ & $1.00 \mathrm{E}+09$ & $4.00 \mathrm{E}+09$ \\
\hline rating & 4,444 & 1 & 3 & 5.807381 & 3.231802 & 10.44455 & 8 & 18 \\
\hline $\mathrm{gb}$ & 4,444 & 0 & 0 & 0.1572907 & 0.3641156 & 0.1325802 & 0 & 1 \\
\hline $\mathrm{mkt}$ iss & 4,444 & 0 & 0 & 0.4889739 & 0.4999347 & 0.2499347 & 1 & 1 \\
\hline cpn fr & 4,444 & 0 & 0 & 0.5609811 & 0.4963232 & 0.2499347 & 1 & 1 \\
\hline gdp & 4,444 & -2.5 & 2.3 & 2.27797 & 0.4865079 & 0.2366899 & 2.4 & 2.9 \\
\hline cpi & 4,444 & -0.3 & 1.6 & 1.666517 & 0.5658958 & 0.320238 & 1.8 & 3.1 \\
\hline rate & 4,444 & 3.3 & 3.5 & 4.535891 & 0.8414223 & 0.7079915 & 5.3 & 5.3 \\
\hline
\end{tabular}

Source: Author's own calculations.

Table 5. Descriptive Statistics of the Sub-Sample of Emerging Countries

\begin{tabular}{|c|c|c|c|c|c|c|c|c|}
\hline & $\mathbf{N}$ & $\min$ & p25 & Mean & St.Dev & variance & p75 & Max \\
\hline Oas & 790 & 5.23 & 162.19 & 427.8635 & 525.2393 & $275,876.4$ & 489.76 & $3,721.58$ \\
\hline iss date & 790 & 2007 & 2016 & 2017.452 & 2.093355 & 2.095909 & 2019 & 2020 \\
\hline Cpn & 790 & 0 & 2.75 & 3.865266 & 1.447725 & 4.382134 & 4.88 & 13.75 \\
\hline amm iss & 790 & $2,328,140$ & $3.00 \mathrm{E}+08$ & $5.27 \mathrm{E}+08$ & $3.89 \mathrm{E}+08$ & $1.52 \mathrm{E}+17$ & $7.00 \mathrm{E}+08$ & $2.35 \mathrm{E}+09$ \\
\hline iss pr & 790 & 96.18 & 99.5 & 99.70023 & 0.4770827 & 0.2276079 & 100 & 101.56 \\
\hline Ten & 790 & 1 & 5 & 7.991139 & 7.242402 & 52.45239 & 10 & 60 \\
\hline min den & 790 & 1 & 150,000 & $240,689.1$ & 266463.9 & $7.10 \mathrm{E}+10$ & 200,000 & $1,000,000$ \\
\hline mod dur & 790 & 0 & 1.83 & 4.814253 & 4.927933 & 24.28453 & 6.1 & 38.68 \\
\hline mac dur & 790 & 0 & 1.9 & 5.032544 & 5.057347 & 25.57675 & 6.39 & 39.49 \\
\hline amm out & 790 & 0 & $2.88 \mathrm{E}+08$ & $5.05 \mathrm{E}+08$ & $3.76 \mathrm{E}+08$ & $1.42 \mathrm{E}+17$ & $6.50 \mathrm{E}+08$ & $2.35 \mathrm{E}+09$ \\
\hline Rating & 790 & 1 & 5 & 7.785443 & 3.914376 & 15.32234 & 10 & 19.5 \\
\hline $\mathrm{Gb}$ & 790 & 0 & 0 & 0.2 & 0.4002534 & 0.1602028 & 0 & 1 \\
\hline mkt iss & 790 & 0 & 1 & 0.7898734 & 0.4076564 & 0.1661838 & 1 & 1 \\
\hline $\mathrm{cpn}$ fr & 790 & 0 & 0 & 0.1911392 & 0.3934476 & 0.154801 & 0 & 1 \\
\hline Gdp & 790 & 1.6 & 2.3 & 2.392279 & 0.4109449 & 0.1688757 & 2.9 & 2.9 \\
\hline Cpi & 790 & 0.1 & 1.6 & 1.732278 & 0.6453567 & 0.4164853 & 2.1 & 2.9 \\
\hline Rate & 790 & 3.3 & 3.5 & 4.467975 & 0.7721219 & 0.5961722 & 5.3 & 8.1 \\
\hline
\end{tabular}

Source: Author's own calculations. 
Due to the fact that the logarithmic form of the dependent variable describes our data better, the decision was taken to compare the models' functional forms.

In order to define the best functional form we conducted the Box-Cox test by means of the Zarembka transformation, which showed that the logarithmic form of the dependent variable describes this model better. The mod_dur and amm_iss regressors were eliminated from the model immediately because of their high relation with the regressors responsible for the Macaulay duration and volume in circulation, consequently, the regressor which characterises the interest rate level of a bank borrowing in the USA market at the date of the issue was eliminated. The Breusch-Pagan and White tests reject the hypothesis of homoscedasticity and are indicative of presence of heteroscedasticity-consistent errors in the model. In order to eliminate the heteroscedasticity errors from the model we used the standard error correction by the White method to obtain robust standard errors. In the final versions of the model insignificant regressors were eliminated (in the model based on the sub-sample of developed markets regressors iss_pr, ten, amm_out, cpn_fr, gdp, cpi were eliminated). In the model with the sub-sample based on the issues from emerging countries insignificant regressors cpi, iss_date, ten, amm_out, min_den, gdp were eliminated. All the remaining regressors from both models are significant at a 5\% level (Tables 6, 7).

Table 6. Final Specification of the Model for the Developed Countries Sample

\begin{tabular}{|c|c|c|}
\hline Variables & $\begin{array}{l}\text { After speci- } \\
\text { fication and } \\
\text { elimination of } \\
\text { heteroscedastici- } \\
\text { ty errors }\end{array}$ & $\begin{array}{l}\text { After specification } \\
\text { and elimination of } \\
\text { heteroscedasticity } \\
\text { errors and elimina- } \\
\text { tion of insignificant } \\
\text { regressors }\end{array}$ \\
\hline \multirow[t]{2}{*}{ cpn } & 0.0772555 & 0.0708643 \\
\hline & $(0.0137837)$ & $(0.0070537)$ \\
\hline \multirow[t]{2}{*}{ iss_date } & 0.0281569 & 0.0265398 \\
\hline & $(0.0061318)$ & $(0.0045656)$ \\
\hline \multirow[t]{2}{*}{ iss_pr } & -0.0120566 & \\
\hline & 0.0084319 & \\
\hline \multirow[t]{2}{*}{ ten } & -0.000727 & \\
\hline & $(0.0011043)$ & \\
\hline \multirow[t]{2}{*}{ min_den } & $8.58 \mathrm{E}-08$ & $9.65 \mathrm{E}-08$ \\
\hline & (3.08E-08) & $(2.87 \mathrm{E}-08)$ \\
\hline \multirow[t]{2}{*}{ mac_dur } & 0.1356471 & 0.138703 \\
\hline & $(0.0131641)$ & $(0.011727)$ \\
\hline
\end{tabular}

\begin{tabular}{|c|c|c|}
\hline Variables & $\begin{array}{l}\text { After speci- } \\
\text { fication and } \\
\text { elimination of } \\
\text { heteroscedastici- } \\
\text { ty errors }\end{array}$ & $\begin{array}{l}\text { After specification } \\
\text { and elimination of } \\
\text { heteroscedasticity } \\
\text { errors and elimina- } \\
\text { tion of insignificant } \\
\text { regressors }\end{array}$ \\
\hline \multirow[t]{2}{*}{ amm_out } & $-1.60 \mathrm{E}-11$ & \\
\hline & $(1.22 \mathrm{E}-11)$ & \\
\hline \multirow[t]{2}{*}{ rating } & 0.1672886 & 0.1686369 \\
\hline & $(0.0038787)$ & $(0.0032413)$ \\
\hline \multirow[t]{2}{*}{$\mathrm{gb}$} & -0.2679526 & -0.2630357 \\
\hline & $(0.0173487)$ & $(0.0171192)$ \\
\hline \multirow[t]{2}{*}{ mkt_iss } & -0.0400964 & -0.0380079 \\
\hline & $(0.0119871)$ & $(0.0116662)$ \\
\hline \multirow[t]{2}{*}{ cpn_fr } & 0.0259183 & \\
\hline & $(0.031989)$ & \\
\hline \multirow[t]{2}{*}{ gdp } & -0.0197566 & \\
\hline & $(0.0122792)$ & \\
\hline \multirow[t]{2}{*}{ cpi } & 0.013715 & \\
\hline & $(0.0130348)$ & \\
\hline \multirow[t]{2}{*}{ Constant } & -51.9652 & -49.93104 \\
\hline & $(12.18104)$ & $(9.195298)$ \\
\hline $\begin{array}{l}\text { Observa- } \\
\text { tions }\end{array}$ & 4,444 & 4,444 \\
\hline R square & 0.7399 & 0.7392 \\
\hline
\end{tabular}

Source: Author's own calculations.

Table 7. Final Specification of the Model for the Emerging Countries Sample

\begin{tabular}{|c|c|}
\hline Variables & $\begin{array}{l}\text { After specification and elimination } \\
\text { of heteroscedasticity errors }\end{array}$ \\
\hline \multirow[t]{2}{*}{ cpn } & 0.0449991 \\
\hline & $(0.0145877)$ \\
\hline \multirow[t]{2}{*}{ iss_pr } & 0.1299713 \\
\hline & $(0.0437996)$ \\
\hline \multirow[t]{2}{*}{ mac_dur } & 0.0853683 \\
\hline & $(0.0178056)$ \\
\hline rating & 0.2139432 \\
\hline
\end{tabular}




\begin{tabular}{|c|c|}
\hline \multirow[t]{2}{*}{ Variables } & $\begin{array}{l}\text { After specification and elimination } \\
\text { of heteroscedasticity errors }\end{array}$ \\
\hline & $(0.006999)$ \\
\hline \multirow[t]{2}{*}{$\mathrm{gb}$} & -0.1838883 \\
\hline & $(0.0574116)$ \\
\hline \multirow[t]{2}{*}{$\mathrm{mkt}$ iss } & 0.3829604 \\
\hline & $(0.0581621)$ \\
\hline \multirow[t]{2}{*}{ cpn_fr } & 0.2030747 \\
\hline & $(0.0490561)$ \\
\hline \multirow[t]{2}{*}{ Constant } & -9.614366 \\
\hline & $(4.376281)$ \\
\hline Observations & 788 \\
\hline R square & 0.8213 \\
\hline F-statistics & 343.4 \\
\hline P-value & 0.0000 \\
\hline
\end{tabular}

As we can see from the obtained results, the variable responsible for the bond being green or not is significant at a $1 \%$ level. The hypothesis of difference in the amount of the yield premium in developed and emerging markets is thereby confirmed. The assumption that in developed markets the negative yield premium on green bonds is larger (higher by modulo) is confirmed. Thus, the green bond issues from developed countries have the yield premium lesser by $26.3 \%$, while from emerging countries it is $18 \%{ }^{13}$.

\section{Conclusion}

In this paper, we analyse the problem of whether investors pay the yield premium on green bonds. For this purpose, we applied a regression analysis and econometric tests in order to establish the significance of the binary variable which designates whether the analysed bond issue is green or not. This methodology was applied to bond issues made in the period from 2008 to the beginning of 2020. In accordance with the obtained results, the existence of a small but statistically significant yield premium from green bonds amounting to $23.4 \%$ in comparison to commensurable green issues was established. This result is of particular importance because our research was conducted with the use of a sample comprising more recent periods (2018, 2019 and the beginning of 2020), while the majority of research on this topic considers earlier time periods. On the one hand, due to a rapid development of the green bond market and, on the other hand, to slowing down of the rate of its growth in the recent years (and possible transition into the maturity stage) the results obtained on the basis of the earlier data may be of no relevance in terms of a description of the contemporary patterns of the market. However, according to our results, even with a slowing down of the market growth rate and the emergence of a great number of market players, there is still a negative premium of green bonds in comparison to other, commensurable bond types.

The second major result of this paper is the proof of a greater degree of marketability of green bonds in comparison with non-green ones. In accordance with our obtained results, the spread decrease for green bonds amounts to $47.9 \%$, which means that they are traded more actively and have a higher marketability.

The third significant result of our research is our confirmation of the hypothesis that the amount of the yield premium for bonds issued by issuers from developed-economy countries and those of issuers from emerging-economy countries differ. The negative yield premium in the green bond market is more pronounced for issuers from developed countries.

The practical importance of the present paper consists in the fact that, in accordance with the obtained results, investors, potential issuing companies, and public authorities may achieve a better understanding of the current situation of the green bond market in global terms and on a disaggregated basis through issuers from developed and emerging countries, and in this context, they may refine their decisions in this sphere.

The main obstacle for this paper was the fact that in the sample the data regarding the main variables such as the rating level, bid, and ask prices were absent, and therefore we had to reduce the sample.

This research may be expanded by taking into consideration the data on social and sustainable bonds, by analysing consistent patterns from the point of view of industry sectors, and by monitoring the amount of the premium across various market development time periods.

\section{References}

1. Zerbib O.D. The effect of pro-environmental preferences on bond prices: Evidence from green bonds. Journal of Banking \& Finance. 2019; 98:39-60. DOI: 10.1016/j.jbankfin.2018.10.012

2. Reboredo J.C. Green bond and financial markets: Comovement, diversification and price spillover effects. Energy Economics. 2018;74:38-50. DOI: 10.1016/j. eneco.2018.05.030

3. Karpf A., Mandel A. Does it pay to be green? A comparative study of the yield term structure of green and brown bonds in the US municipal bonds market. SSRN Electronic Journal. 2017. DOI: 10.2139/ ssrn.2923484

\footnotetext{
${ }^{13}$ Interpretation of results in percent on the basis of use of the dependent variable logarithm in the econometric model.
} 
4. Gianfrate G., Peri M. The green advantage: Exploring the convenience of issuing green bonds. Journal of Cleaner Production. 2019;219:127-135. DOI: 10.1016/j.jclepro.2019.02.022

5. Preclaw R., Bakshi A. The cost of being green. Barclays Research. 2015. URL: https://www. environmental-finance.com/assets/files/US_Credit_ Focus_The_Cost_of_Being_Green.pdf

6. Nanayakkara M., Colombage S. Do investors in green bond market pay a premium? Global evidence. Applied Economics. 2019;51(40):4425-4437. DOI: $10.1080 / 00036846.2019 .1591611$

7. Partridge C., Medda F.R. The evolution of pricing performance of green municipal bonds. Journal of Sustainable Finance \& Investment. 2020;10(1):44-64. DOI: 10.1080/20430795.2019.1661187

8. Fatica S., Panzica R., Rancan M. The pricing of green bonds: Are financial institutions special? JRC Working Papers in Economics and Finance. 2019;(7). URL: https://publications.jrc.ec.europa. eu/repository/bitstream/JRC116157/jrc116157_ faticapanzicarancan_gbpricing_jrc_report_01.pdf

9. Chiesa M., Barua S. The surge of impact borrowing: The magnitude and determinants of green bond supply and its heterogeneity across markets. Journal of Sustainable Finance and Investment. 2019;9(2):138161. DOI: 10.1080/20430795.2018.1550993

10. Bachelet M. J., Becchetti L., Manfredonia S. The green bonds premium puzzle: The role of issuer characteristics and third-party verification. Sustainability. 2019;11(4):1098. DOI: 10.3390/ su1 1041098

11. Febi W., Schäfer D., Stephan A., Sun C. The impact of liquidity risk on the yield spread of green bonds. Finance Research Letters. 2018;27:53-59. DOI: 10.1016/j.frl.2018.02.025

12. Garay U., González M., Rosso J. Country and industry effects in corporate bond spreads in emerging markets. Journal of Business Research. 2019;102:191-200. DOI: 10.1016/j.jbusres.2017.09.021

13. Bao J., Hou K. De facto seniority, credit risk, and corporate bond prices. The Review of Financial Studies. 2017;30(11):4038-4080. DOI: 10.1093/rfs/ hhx082

14. Lu C.-W., Chen T.-K., Liao H.-H. Information uncertainty, information asymmetry and corporate bond yield spreads. Journal of Banking \& Finance. 2010;34(9):2265-2279. DOI: 10.1016/j. jbankfin.2010.02.013
15. Zhou R., Xiong Y., Liu T., Li J. Macroeconomic determinants of credit spreads: An empirical comparison between Chinese and American corporate bonds. Asian Economic and Financial Review. 2019;9(5):604-616. DOI: 10.18488/journal. aefr.2019.95.604.616

16. Chen T., Liao H., Tsai P. Internal liquidity risk in corporate bond yield spreads. Journal of Banking \& Finance. 2011;35(4):978-987. DOI: 10.1016/j. jbankfin.2010.09.013

17. Mukherjee K. Demystifying yield spread on corporate bonds trades in India. Asia-Pacific Financial Markets. 2019;26(2):253-284. DOI: 10.1007/s10690-01809266-w

18. Friewald N., Nagler F. Over-the-counter market frictions and yield spread changes. The Journal of Finance. 2019;74(6):3217-3257. DOI: 10.1111/ jofi. 12827

19. Rojahn J., Zechser F. The effect of corporate diversification on credit risk: New evidence from European credit default swap spreads. Accounting and Finance. 2019;59(4):2679-2704. DOI: 10.1111/ acfi. 12306

20. Guidolin M., Orlov A., Pedio M. The impact of monetary policy on corporate bonds under regime shifts. Journal of Banking \& Finance. 2017;80:176-202. DOI: 10.1016/j.jbankfin.2017.03.011

21. De Santis R.A. Unobservable country bond premia and fragmentation. Journal of International Money and Finance. 2018;82:1-25. DOI: 10.1016/j. jimonfin.2017.12.003

22. Pereira J., Sorwar G., Nurullah M. What drives corporate CDS spreads? A comparison across US, UK and EU firms. Journal of International Financial Markets, Institutions and Money. 2018;56:188-200. DOI: 10.1016/j.intfin.2018.02.002 


\section{Appendix. Coding of the Credit Rating Variable}

Table. Transformation of Literal Rating Scales of the Variable (RATING) into Integers

\begin{tabular}{|c|c|c|}
\hline Numerical scale & Moody's & Fitch/S\&P \\
\hline 1 & Aaa & AAA \\
\hline 2 & Aal & $\mathrm{AA}+$ \\
\hline 3 & $\mathrm{Aa} 2$ & AA \\
\hline 4 & Aa3 & AA- \\
\hline 5 & $\mathrm{~A} 1$ & $\mathrm{~A}+$ \\
\hline 6 & $\mathrm{~A} 2$ & A \\
\hline 7 & $\mathrm{~A} 3$ & A- \\
\hline 8 & Baal & $\mathrm{BBB}+$ \\
\hline 9 & Baa2 & $\mathrm{BBB}$ \\
\hline 10 & Baa3 & BBB- \\
\hline 11 & Bal & $\mathrm{BB}+$ \\
\hline 12 & $\mathrm{Ba} 2$ & $\mathrm{BB}$ \\
\hline 13 & $\mathrm{Ba} 3$ & BB- \\
\hline 14 & $\mathrm{~B} 1$ & $\mathrm{~B}+$ \\
\hline 15 & $\mathrm{~B} 2$ & B \\
\hline 16 & B3 & B- \\
\hline 17 & Caal & $\mathrm{CCC}+$ \\
\hline 18 & $\mathrm{Caa} 2$ & CCC \\
\hline 19 & $\mathrm{Caa} 3$ & CCC- \\
\hline 20 & $\mathrm{Ca}$ & C \\
\hline 21 & $\mathrm{D}$ & $\mathrm{D}$ \\
\hline
\end{tabular}

Source: Author's own calculations. 